\title{
Identification and Selection for Salt Tolerance in Alfalfa (Medicago sativa L.) Ecotypes via Physiological Traits
}

\author{
Hassan MONIRIFAR ${ }^{1)}$, Maryam BARGHI'2) \\ ${ }^{1)}$ East Azarbayjan Agriculture and Natural Resources Research Center, Tabriz, Iran; monirifar@yahoo.com \\ 2) Agricultural Biotechnology Research Inistitute, West and North West Region of Iran, Tabriz, Iran; maryam_barghi40@yahoo.com
}

\begin{abstract}
Salt stress is a serious environmental problem throughout the world which may be partially relieved by breeding cultivars that can tolerate salt stress. Plant breeding may provide a relatively cost effective short-term solution to the salinity problem by producing cultivars able to remain productive at low to moderate levels of salinity. Five alfalfa cultivars, 'Seyah-Roud', 'Ahar-Hourand', 'Oskou', 'Malekan' and 'Sefida-Khan' were assessed for salt tolerance at mature plant stage. A greenhouse screening system was used to evaluate individual alfalfa plants grown in perlit medium, and irrigated with water containing different amounts of $\mathrm{NaCl}$. Three salt levels were achieved by adding 0,100 and $200 \mathrm{mM} \mathrm{NaCl}$ to Hoagland nutrient solution, respectively. Forage yield, sodium and potassium contents and K/Na ratio was determined. Also, leaf samples were analyzed for proline and chlorophyll contents. The ecotypes Seyha-Roud and 'Sefida-Khan' had comparatively less sodium contents than 'Oskou,' 'Ahar-Hourand' and 'Malekan' ecotypes, also potassium content increased under saline condition. Forage yield of different alfalfa ecotypes was significantly influenced by the salinity. The ecotypes 'Malekan', Ahar- Hourand and 'Oskou' were successful in maintaining forage yield under salinity stress. Sodium contents increased due to salinity in all alfalfa ecotypes however ecotypes 'Ahar-Hourand' and 'Malekan' maintained the highest leaf Na concentration. They showed higher content of $\mathrm{K}$ than other ecotypes but had lower K/Na ratio. It was concluded that, two ecotypes 'Malekan' and 'Ahar-Hourand' were better.
\end{abstract}

Keywords: chlorophyll, lucerne, proline, salinity, yield

\section{Introduction}

Nearly 10 percent of the earth's land is salt-affected and an estimated 10 million ha of agricultural land are lost annually due to salinization and water logging. Salinity of soil and water resources is a serious threat in many parts of Iran. The estimated land area affected by salinity varies between 16 to 23 Mha (Siadat et al., 1997). These figures include both cultivated and barren lands. No exact data is available on intensity of this problem in the arable lands. The main difficulty in this regard is the temporal variations of salinity during the growing season, due to the effects of irrigation water, which add or leach the salts. In general, 50 percent of all growing areas of Iran are encountered by high-salt concentration conditions and drought (Siadat, 2004).

The area of saline soils in East Azarbaijan is estimated to be 200000 hectare. The surrounding area of Urumiyeh Lake has high potentiality of agricultural development in future. There exists vast land without use in many areas due to some unfavorable natural conditions for farming such as high saline soil (Kazmeinkhah, 2004).

Rapidly growing demand for livestock products increased due to increasing human population changing the diet regimes. To provide more animal products, more for- age and fodder are also needed. Much of the cropland affected by salinity is in traditional alfalfa growing regions of the world. Forage yield of alfalfa decreases $7.3 \%$ for each $\mathrm{dSm} \mathrm{m}^{-1}(\approx 11 \mathrm{mM} \mathrm{NaCl})$ increase above a threshold of 2.0 $\mathrm{dSm}^{-1}(\approx 22 \mathrm{mM} \mathrm{NaCl})$ (Johnson et al., 1992). Seedling alfalfa yield is decreased by $50 \%$ at $8.9 \mathrm{dS} \mathrm{m^{-1 }}(\approx 97 \mathrm{mM}$ $\mathrm{NaCl}$ ) (Maas \& Hoffman, 1977).

Reclamation, drainage and improved irrigation practices might reduce the severity and spread of salinization in some regions, but costs of these practices are generally prohibitive (Johnson et al., 1992). Plant breeding may provide a relatively cost effective short-term solution to the salinity problem by producing cultivars able to remain productive at low to moderate levels of salinity. However, breeding for improved salt tolerance in many crop plants, including alfalfa, has progressed slowly (Blum, 1988; Johnson et al., 1992; Noble et al., 1984).

Flowers and Yeo (1995) suggested five possible ways, which were appropriate at that time, to develop salt tolerant crops: (1) develop halophytes as alternative crops; (2) use interspecific hybridization to raise the tolerance of current crops; (3) use the variation already present in existing crops; (4) generate variation within existing crops by using recurrent selection, mutagenesis on tissue culture, and (5) breed for yield rather than tolerance. Tolerance breeding 
64

by transformation is another important approach had been missed by Flower and Yao, is now being widely advocated (Flowers, 2004).

Salinity research in alfalfa has focused primarily on germination (Carlson et al., 1983; Allen et al., 1986., Dobrenz et al., 1989) and seedling establishment (Ashraf et al., 1987; Mckimmie and Dobrenz, 1987) in the presence of $\mathrm{NaCl}$. Several reports indicate that alfalfa has the genetic potential for improved salt tolerance and that plant breeding may be the solution for increasing yield in saline environments (Johnson et al., 1992; Mohammad et al., 1984; Noble et al., 1984).

Development of salt tolerance in crops depends ultimately on two factors. Availability of genetic variation by screening and selection of those plants with superior performance when exposed to such stress is very important (Epstein et al., 1980; Shannon, 1984). The presence of phenotypic variation for salt tolerance was reported for alfalfa cultivars (Al-Khatib et al., 1993; Noble et al., 1984).

It might therefore be that selection of highly salt tolerant genotypes between and within cultivars could be expected to provide useful material for further breeding, and for experimental comparisons (Al-Khatib et al., 1993).

Monirifar et al., (2004) reported the presence of phenotypic variation between some Azarbaijan alfalfa cultivars at different salinity levels and changing in forage yield resulting from saline stress.

This research was conducted to evaluate and selection of new Azarbaijan alfalfa cultivars for salt tolerance.

\section{Materials and methods}

For the present study five local lucerne cultivars, 'Seyah-Roud', 'Ahar-Hourand', 'Oskou', 'Malekan' and 'Sefida-Khan' were used. This choice was based upon the results determination of general combining ability with polycross test project (Monirifar, 2008). A greenhouse screening system previously described by Johnson $e t$ al., (1991) was used to evaluate of individual alfalfa plants grown in at perlit medium, and irrigated with water containing different amounts of $\mathrm{NaCl}$. $\mathrm{NaCl}$ levels observed in agricultural regions where salinity is a problem were selected (Kazmeinkhah, 2004). Two sterilized seeds of each five cultivars were sown in individual $70 \mathrm{~mm} \times 0.4 \mathrm{~m}$ cylindrical containers containing $60 \pm 1.5 \mathrm{~g}$ (dry wt., mean \pm SE) of perlite and thinned to one plant per container at $14 \mathrm{~d}$. Containers placed in a randomized layout in green house with a $16 \mathrm{~h}$ photoperiod and night and day temperatures of approximately 16 and $22^{\circ} \mathrm{C}$ respectively. The pots were irrigated with Hoaglands solution (Tab. 1).

Plants were not inoculated with Rhizobium (nitrogen was supplied in the nutrient solution), as there are no differences in salinity response between nodulated and nonnodulated Lucerne plants (Bernstein and Ogata, 1966).

Three salt levels were achieved by adding 0,100 and $200 \mathrm{mM} \mathrm{NaCl}$ to water, respectively. Forage from each
Tab. 1. Element composition of nutrient solution were used in experiment

\begin{tabular}{lc}
\hline \multicolumn{1}{c}{ Chemical combination } & mg/liter \\
\hline $\mathrm{KH}_{2} \mathrm{PO}_{4}$ & 136 \\
$\mathrm{KNO}_{3}$ & 505 \\
$\mathrm{Ca}\left(\mathrm{NO}_{3}\right) \cdot 4 \mathrm{H}_{2} \mathrm{O}$ & 1180 \\
$\mathrm{MgSO}_{4} \cdot 7 \mathrm{H}_{2} \mathrm{O}$ & 492 \\
$\mathrm{H}_{3} \mathrm{BO}_{3}$ & 2.86 \\
$\mathrm{MnCl}_{2} \cdot 4 \mathrm{H}_{2} \mathrm{O}$ & 1.81 \\
$\mathrm{ZnSO}_{4} \cdot 7 \mathrm{H}_{2} \mathrm{O}$ & 0.22 \\
$\mathrm{CuSO}_{4} \cdot 5 \mathrm{H}_{2} \mathrm{O}$ & 0.08 \\
$\mathrm{CoCl}_{2} \cdot 6 \mathrm{H}_{2} \mathrm{O}$ & 0.025 \\
$\left(\mathrm{NH}_{4}\right) 6 \cdot \mathrm{Mo}_{7} \mathrm{O}_{24} \cdot 4 \mathrm{H}_{2} \mathrm{O}$ & 10.0 \\
$\mathrm{FeSO}_{4} \cdot 7 \mathrm{H}_{2} \mathrm{O}$ & 27.8 \\
\hline
\end{tabular}

plant was harvested at $10 \%$ bloom by clipping $4 \mathrm{~cm}$ above and was measured. Sodium and potassium analyses were made on three $200 \mathrm{mg}$ samples from each ecotype in each tolerance class. Material was ashed at $460^{\circ} \mathrm{C}$ for $18 \mathrm{~h}$ and dissolved in $5 \mathrm{ml}$ of $2 \mathrm{M} \mathrm{HNO}_{3}$. This method permitted all two ions to be readily analyzed from the one sample. Sodium and potassium were estimated by atomic absorption spectrophotometer. A randomized complete block design with a split- plot arrangement was used with $\mathrm{NaCl}$ levels as main plots and ecotypes as subplots.

Proline estimation: Leaf tissue was frozen in liquid nitrogen and stored until required, then it was homogenized in methanol: chloroform: water (MCW 12:5:1 /V) using $0.2 \mathrm{~g}$ tissue per $2 \mathrm{~cm}^{3}$ of MCW at room temperature and proline contents estimated, also leaves samples analyzed for chlorophyll contents( Ashraf et al., 1994).

\section{Results and discussion}

Leaf chemical analysis of different alfalfa ecotypes indicated that sodium $(\mathrm{Na})$ contents increased under saline condition (Tab. 2) but there were not significant difference, among ecotypes. The ecotypes Seyha-Roud and Sefida-Kkhan had comparatively less sodium contents than 'Oskou', 'Ahar-Hourand' and 'Malekan' ecotypes. Results also indicated that potassium content increased under saline condition (Tab. 2). However, ecotypes 'Ahar-Hourand' and 'Malekan' maintained higher potassium contents than other under saline condition. Biochemical analysis of leaves of alfalfa ecotypes indicated proline accumulation and chlorophyll contents increased under saline condition (Tab.3). Alfalfa ecotypes 'Malekan' and 'Oskou' showed higher accumulation of proline than others (Tab. 3). Similarly minimum reductions in chlorophyll content were in 'Malekan' and 'Ahar-Hourand' ecotypes.

Forage yield of different alfalfa ecotypes was significantly influenced by the salinity (Tab. 3). The ecotype 'Malekan' showed minimum reduction, when compared with control, where as maximum reduction over control 
Tab. 2. Effects of salinity on sodium $(\mathrm{Na})$, potassium $(\mathrm{k})$ contents and $\mathrm{K} / \mathrm{Na}$ ratio in different alfalfa ecotypes

\begin{tabular}{ccccccccccc}
\hline \multirow{2}{*}{ Ecotype } & \multicolumn{3}{c}{$\mathrm{Na}^{*}$} & \multicolumn{3}{c}{$\mathrm{Ka}$} & \multicolumn{4}{c}{$\mathrm{K} / \mathrm{Na}$} \\
\cline { 2 - 10 }$y$ & $0 \mathrm{mM}$ & $100 \mathrm{mM}$ & $200 \mathrm{mM}$ & $0 \mathrm{mM}$ & $100 \mathrm{mM}$ & $200 \mathrm{mM}$ & $0 \mathrm{mM}$ & $100 \mathrm{mM}$ & $200 \mathrm{mM}$ \\
\hline 'Seyah-Roud' & 3465 & 67.29 & 68.47 & 40.44 & 59.70 & 60.40 & 1.16 & 0.89 & 0.84 \\
'Ahar-Hourand' & 39.96 & 66090 & 83.32 & 43.57 & 59.47 & 69.16 & 1.59 & 0.89 & 0.83 \\
'Oskou' & 42.12 & 62.28 & 76.24 & 44.85 & 56.74 & 64.98 & 1.10 & 0.94 & 0.83 \\
'Malekan' & 39.07 & 73.10 & 83.22 & 43.05 & 63.12 & 69.10 & 1.10 & 0.87 & 0.83 \\
'Sefida-Khan' & 35.93 & 57.7 & 79.68 & 41.19 & 53.67 & 67.01 & 1.14 & 0.95 & 0.84 \\
Mean & 38.34 & 65.33 & 78.19 & 42.62 & 58.54 & 66.13 & 1.12 & 0.91 & 0.85 \\
LSD(0.05) & 4.1654 & 9.2064 & 7.1861 & 2.4576 & 5.4329 & 4.2397 & 0.0413 & 0.0477 & 0.03378 \\
\hline
\end{tabular}

"The unit is $\mathrm{mg} \mathrm{g}^{-1} \mathrm{D} . \mathrm{W}$.

was recorded in 'Sefida-Khan'. The ecotypes 'Malekan', Ahar- Hourand and 'Oskou' were successful in maintaining forage yield more than $60 \%$ under salinity stress.

Sodium contents increased due to salinity in all alfalfa ecotypes however ecotypes 'Ahar-Hourand' and 'Malekan' maintained the highest leaf $\mathrm{Na}$ concentration. Minimum $\mathrm{Na}$ content was recorded by "Sefida-Khan" in $100 \mathrm{mM}$ and by 'Seyah-Roud' in $200 \mathrm{mM} \mathrm{NaCl}$, respectively (Tab. 2).

In studies where salinity is developed with $\mathrm{NaCl}$, a focus has been the transport system that is involved in the utilization of $\mathrm{Na}$ as an osmotic solute (Yasar et al., 2006). A significant positive correlation was observed between sodium and potassium contents of alfalfa ecotypes under sodium chloride concentration, so 'Malekan' and 'AharHourand' alfalfa ecotypes showed the higher content of potassium. It is reported that salt tolerance is associated with $\mathrm{K}$ contents (Ashraf and Sarwar, 2002), because of its involvement in osmotic regulation and competition with $\mathrm{Na}$ (Ashraf et al., 2005). Regulation of K uptake and prevention of $\mathrm{Na}$ entry, efflux of $\mathrm{Na}$ from cell are the strategies commonly used by plants to maintain desirable $\mathrm{K} / \mathrm{Na}$ ratio in the cytosole but in the present study, the tolerant ecotype aren't expressing the same trend for $\mathrm{K} / \mathrm{Na}$ ratios.

Ecotypes 'Malekan' and 'Ahar-Hourand' ecotypes showed high content of $\mathrm{Na}$ and $\mathrm{K}$ than other ecotypes but had low $\mathrm{K} / \mathrm{Na}$ ratio (Tab. 2). $\mathrm{K} / \mathrm{Na}$ ratio is the criteria which is established by the scientist and the genetically approved for salt tolerance (Khan et al., 2009).

There are different reports about chlorophyll content in plants under stress (Alamgir and Ali, 1999; Khan et al., 2009). Khan et al., (2009) reported that chlorophyll contents of wheat genotypes decreased under stress but Alamgir and Ali (1999) observed an increase in chlorophyll contents in 6 genotypes of rice. Our results are in agreement with this worker where in all ecotypes, chlorophyll contents are increasing. The increase is significant in sensitive ecotype in comparison to tolerant.

Accumulation of solutes especially proline is a common observation under stress condition (Ashraf et al., 1994). It is reported that proline is an important osmolyte to adjust the plant under drought/saline condition. In the present study, the accumulation of proline was commonly observed in all ecotypes however, the ecotypes 'Malekan' followed by 'Oskou' and 'Sefida-Khan' at $100 \mathrm{mM}$ and 'Oskou' by 'Malekan' and 'Sefida-Khan' at $200 \mathrm{mM} \mathrm{NaCl}$, respectively(Tab. 3). These ecotypes are the best performing ones and higher forage yield under salinity stress. A similar observation was recorded in wheat (Khan et al., 2009). There are however reasons to believe that proline accumulation may play a role in the salinity tolerance. Firstly it is an osmolyte accumulated under stress in almost all the plant species. Secondly a high proline concentration has been described in organs which naturally have low water contents such as seed and inflorescence (Khan et al., 2009).

\section{Conclusions}

It was concluded that on the basis of less than $40 \%$ reduction in forage yield, two ecotypes 'Malekan' and 'AharHourand' were better.

Tab. 3. Effect of salinity on accumulation of proline, total chlorophyll and forage yield of different alfalfa ecotypes

\begin{tabular}{cccccccccc}
\hline & \multicolumn{3}{c}{ Proline $(\mathrm{molg}-1)$} & \multicolumn{3}{c}{ Chlorophyll(mg g-1) } & \multicolumn{3}{c}{ Forage yield(gr/plant) } \\
\cline { 2 - 11 } Ecotype & $0 \mathrm{mM}$ & $100 \mathrm{mM}$ & $200 \mathrm{mM}$ & $0 \mathrm{mM}$ & $100 \mathrm{mM}$ & $200 \mathrm{mM}$ & $0 \mathrm{mM}$ & $100 \mathrm{mM}$ & $200 \mathrm{mM}$ \\
\hline 'Seyah-Roud' & 3.57 & 5.19 & 11.43 & 49.72 & 54.17 & 52.64 & 2.61 & 1.59 & 0.99 \\
'Ahar-Hourand' & 3.55 & 5.57 & 10.94 & 38.75 & 57.57 & 53.78 & 2.62 & 1.75 & 1.21 \\
'Oskou' & 7.38 & 8.26 & 17.71 & 47.08 & 52.58 & 56.87 & 1.86 & 1.27 & 1.01 \\
'Malekan' & 4.41 & 12.91 & 14.65 & 42.37 & 52.83 & 48.55 & 2.32 & 1.89 & 1.27 \\
'Sefida-Khan' & 4.93 & 7.65 & 14.38 & 47.50 & 53.74 & 52.38 & 2.48 & 1.39 & 0.85 \\
Mean & 4.77 & 7.92 & 13.82 & 45.04 & 54.18 & 52.84 & 2.38 & 1.58 & 1.06 \\
LSD (5\%) & 1.4284 & 2.6743 & 4.4616 & 5.4990 & 3.2765 & 3.3702 & 0.3050 & 0.2136 & 0.1984 \\
\hline
\end{tabular}


66

\section{References}

Alamgir, A. N. M. and M. Y. Ali (1999). Effect of salinity on leaf pigments, sugar and protein concentrations and chloroplast ATPase activity of rice (Oryza sativa L.). Bangladesh Journal of Botany. 28:145-149.

Al-Khatib, M., T.McNeilly and J.C.Collins (1993). The potential of selection and breeding for improved salt tolerance in Lucerne (Medicago sative L.) Euphytica. 65:43-51.

Allen. S. Q., A. K. Dobrenz, M. Scharnhorst and J. E. A. Stoner (1986). Heritability of $\mathrm{NaCl}$ tolerance in germinating alfalfa seeds. Agron. J. 77:99-105.

Ashraf, M., T. McNeilly and A. D. Bradshaw (1987). Selection and heritability of tolerance to sodium chloride in four forage species. Crop Sci. 227:232-234.

Ashraf, M. Y., Azmi, A. R., Khan, A. H., and S. A. Ala (1994). Effect of water stress on total phenols, peroxidase activity and chlorophyll content in wheat. Acta physiologiae plantarum. 16(3):185-186.

Ashraf, M. Y. and G. Sarwar (2002). Salt tolerance potential in members of Brassicaceae. Physiological studies on water relations and mineral contents, pp. 237-245. In: Prospects for saline agriculture (R. Ahmad and K. A. Malik Eds.). Kluwer academic publishers, Netherland.

Ashraf, M. Y., K. Akhtar, G. Sarwar and M. Ashraf (2005). Role of rooting system in salt tolerance potential of different guar accessions. Agronomy of sustainable development. 25:243249.

Bernstein, L. and G. Ogata (1966). Effects of salinity on nodulation, nitrogen fixation and growth of soybeans and alfalfa. Agron. J. 58:201-204.

Blum, A. (1988). Plant breeding for stress environments. CRC Press, Boca Ration, FL.

Carlson, J. R., R. L. Ditterline, J. M. Martin, D. C. Sands and R. E. Lund (1983). Alfalfa seed germination in antibiotic agar containing $\mathrm{NaCl}$. Crop Sci. 23:882-885.

Dobrenz,A. K., D. L. Robinson, S. E. Smith and D. C. Poteet (1989). Registration of AZ-GERM SALT-II nondormant alfalfa germplasm. Crop Sci. 29:293.

Epstein, E. and J. J. Norlyn, G. W. Rush, R. W. Kingsbury, D. W. Kelly, G. A. Cunningham and A. F. Wrona (1980). Saline culture of crops: a genetic approach. Science. 210:399-404.

Flowers, T. J. and A. R. Yeo (1995). Breeding for salinity resistance in crop plants-where next? Australian journal of plant physiology. 22:875-884.

Flowers, T. J. (2004).Improving crop salt tolerance. J. of experimental botany. 55:307-319.

Johnson, D. W., S. E. Smith and A. K. Dobrenz (1992). Genetic and phenotypic relationships in response to $\mathrm{NaCl}$ at different development stages in alfalfa. Theor. Appl. Genet.

Kazmeinkhah, K. (2004). Agricultural development in the saline soils of East Azarbaijan. International scientific symposium, Ganja. Azerbaijan.

Khan, M. A., M. U. Shirazi, M. A. Khan, S. M. Mujtaba, E. Islam, S. Mumtaz, A. Shereen, R. U. Ansari and M. Yasin Ashraf (2009). Role of proline, K/Na ratio and chlorophyll content in salt tolerance of wheat (Triticum aestivum L.). Pak. J. Bot. 41(2):633-638.

Mass. E. V and G. J. Hoffman(1977). Crop salt tolerance current assessment. J. Irrig Drainage Div. Am. Soc. Civil. Eng. 103: 115-134.

McKimmie, T. and A. K. Dobrenz (1987). A method for evaluation of salt tolerance during germination, emergence, and seedling establishment. Agron. J. 79:943-945.

Monirifar, H. (2008). Determination of general combining ability with polycross test for Azarbaijan alfalfa ecotypes. Final report, project no: 101-12-81149. East Azarbayjan Agriculture and Natural Resources Research Center, Tabriz, Iran.

Monirifar, H., M. Valizadeh, R. Mohammadian, M. S. Abedi and A. O. Milani (2004). Variation for tolerance in five alfalfa cultivars. International scientific symposium, Ganja. Azerbaijan.

Noble, C. L., G. M. Halloran and D. W. West (1984). Identification and selection for salt tolerance in Lucerne (Medicago sative L.). Aust. J. Agric. Res. 35: 239-252.

Shanon, M. C. (1984). Breeding, selection and genetics of salt tolerance, pp.231- 254. In: Salt salinity tolerance in plants. (John Wiley and Sons Eds.), R>C > staples and G>H toenniessen.

Siadat, H., M. Bybordi and M. J . Malakouti (1997). Salt affected soils of Iran: A country report. International symposium on "Sustainable management of salt affected soils in the arid ecosystem". Cairo, Egypt.

Siadat, H.( 2004). Agriculture and salinity in Iran. In www.unu. edu/env/land/iran-1/02-siadat per cent20paper.doc/.

Yasar, F., S. Ellialtioglu and S. Kusvuran (2006). Ion and lipid peroxide content in sensitive and tolerant eggplant callus cultured under salt stress. Europ. J. Hort. Sci. 41(4):169172. 